\title{
Dieta saludable, alimentos puros y purificación en el mundo grecolatino
}

\author{
Healthy Diet, Pure Food and Purification \\ in the Greco-Roman World
}

\author{
Amalia LEJAVITZER LAPOUJADE \\ Centro de Estudios Clásicos, IIFL, Universidad Nacional Autónoma de México \\ amalia.lejavitzer@ucu.edu.uy / alejavitzer@hotmail.com
}

\begin{abstract}
RESUMEN: A partir del análisis de diversos textos de autores de la antigüedad clásica, entre ellos De re coquinaria atribuido a Apicio y De abstinentia de Porfirio, este artículo analiza la noción de pureza alimentaria, como condición no sólo para el mantenimiento de la salud mediante una dieta saludable, sino también como una preocupación del individuo que busca ser óptimo en el terreno de la moral. En primer lugar, se estudia el concepto de dieta, como parte de la terapéutica. Para los griegos y romanos de la antigüedad, además de una alimentación saludable, descanso y ejercicios, la dieta incluía baños y purgas, ambos elementos vinculados con la idea de purificación. En segundo lugar, se comparan los términos latinos usados para describir un alimento "puro": crudus, recens, viridis y purus, en especial referidos al aceite de oliva y a la miel, los cuales son considerados los alimentos puros por antonomasia. Se concluye con una definición de pureza alimentaria, es decir, referida a aquellos alimentos que no requieren ni cocción ni preservación para su consumo, y que pueden ser consumidos sin mezcla ni adición de ningún producto, en donde, además, la intervención del hombre es nula o mínima. En suma, la noción de pureza trasciende los límites de la dietética, cobra un valor metafórico que la proyecta en la dimensión de la moral.
\end{abstract}

ABSTRACT: From the texts of authors of Classical Antiquity (De abstinentia by Porphyry and De re coquinaria attributed to Apicius, among others), this paper analyzes the notion of pure food and their implication in the diet and over it. First, it studies the concept of diet, as a part of the therapeutic, that is, one of the medical instruments to restore health. For ancient Greeks and Romans, in addition to healthy eating, rest and exercise, the diet includes baths and purges; both elements are related to the idea of purity. Secondly, this paper shows the Latin terms that are used to describe pure food, crudus, recens, viridis and purus, specifically in the cases of olive oil and honey, which are considered the pure foods most characteristics. To conclude, pure food requires neither cooking nor preservation for consumption, and also can be consumed without mixing or adding any element to the product itself. In consequence, the notion of purity is associated not only with a dietetic domain, but this notion also reaches ethical and metaphoric dimensions.

PAlabRas ClAVE: dieta saludable; alimentos puros; purificación; alimentación en la antigüedad grecorromana; Porfirio; Apicio.

Keywords: Healthy Diet; Pure Food; Purity; Food in Graeco Roman Antiquity; Porphyry; Apicius. 
RECIBIDO: 18 de noviembre de 2015 - ACEPTADO: 29 de enero de 2016.

DOI: 10.19130/iifl.nt.2016.33.2.711

La preocupación del ser humano por seguir una alimentación saludable y por llevar a cabo dietas para purificar el organismo no es nueva.

El actual significado de la palabra dieta, referido exclusivamente a la privación de ciertos alimentos, refleja sólo un aspecto del concepto clásico del término, pues díaı $\alpha$, en griego, y diaeta, en latín, se referían sí a qué alimentos comer, pero sobre todo a cómo vivir, a cómo llevar una vida saludable en cuerpo y alma.

La dieta implicaba seguir un género de vida saludable, que incluyera, por supuesto, una alimentación sana, pero también ejercicio frecuente, periodos de descanso, purgas habituales y baños. El papel de la dieta en la medicina antigua fue, ante todo, el de conservar la salud y el de prevenir la enfermedad, causada por la alteración del equilibrio interno. La dieta, pues, tenía la función de restaurar el equilibrio fracturado, o de impedir, mediante su cumplimiento, que dicho equilibrio se quebrantara.

Para Hipócrates, la salud se logra por la justa proporción entre los alimentos ingeridos y los ejercicios físicos realizados, de manera que no se diera un desequilibrio, ni por exceso ni por defecto de ellos: "en efecto, si, además de esto, hubiera sido posible descubrir en cada uno la medida de alimento para cada naturaleza, y la cantidad adecuada de ejercicios, sin tener exageración, ni por demasía ni por carencia, se hubiera descubierto, con precisión, la salud para cada hombre". 1

Los tratados Sobre la dieta, Sobre la dieta en las enfermedades agudas, Sobre el uso de los líquidos, Sobre el alimento, entre otros que se incluyen en el Corpus Hippocraticum, revelan la importancia que el médico de Cos otorgó a la dieta. En Sobre la dieta, destaca la necesidad que

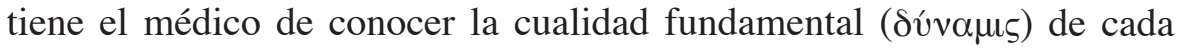
alimento y bebida, ${ }^{2}$ a fin de saber qué efectos producirán en el paciente,

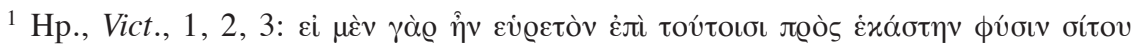

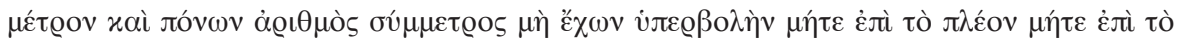

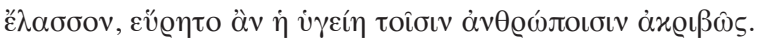

${ }^{2}$ El catálogo de las propiedades de alimentos y bebidas, uno de los más completos y extensos de los que se tiene noticia (abarca los capítulos 39 a 56 del libro segundo de Sobre la dieta), inicia con los cereales: la cebada, el trigo y la espelta (y los panes y bebidas elaborados a partir de ellos); sigue con las leguminosas, las carnes, las aves, los 
antes de prescribirle un régimen para recomponer la alteración del equilibrio, que lo ha llevado a la enfermedad.

En Sobre la dieta en las enfermedades agudas, Hipócrates expresa que, incluso en las enfermedades agudas - aquellas que llevan a la muerte a la mayoría de los hombres,- 3 el mantener un régimen alimenticio sencillo, basado en la administración constante de las tisanas ${ }^{4}$ y de algunas otras bebidas medicinales, como el hidromiel ${ }^{5}$ y el oximiel, ${ }^{6}$ permitirá al paciente recobrar la salud. En estas bebidas, como lo deja en evidencia su nombre, la miel es un ingrediente fundamental de la composición.

De hecho, para los médicos antiguos, la dieta constituye una de las tres partes de la terapéutica. Celso lo sintetiza de esta manera, la medicina "se divide en tres partes: una que cura por medio de la dieta; otra, por medio de medicamentos, y la tercera que lo hace por medio de la mano. Los griegos llamaron a la primera, dietética; a la segunda, farmacéutica, y a la tercera cirugía". 7

Por su parte, Galeno situó a la dieta en un lugar prominente dentro de su arte médica. ${ }^{8}$ Consideró que la dietética era el fundamento primordial de la terapéutica, pues sólo mediante un régimen de vida adecuado - alimentación, ejercicio, baños y descanso - se lograba mantener el equilibrio ideal de los humores corporales y, con ello, alcanzar y mantener la salud. ${ }^{9}$

Galeno conservó la teoría hipocrática de los cuatro humores, la cual concebía el cuerpo humano compuesto por la sangre, caracterizada por

pescados y mariscos, los huevos y el queso; por último, concluye con las bebidas (agua, vino, vinagre y miel), los vegetales y las frutas.

${ }^{3}$ Cf. Hp., Acut., 5.

${ }^{4}$ Cf. ibid., 11 .

${ }^{5} \mathrm{Cf}$. ibid., 55 .

${ }^{6}$ Cf. ibid., 58.

7 Cels., proem., 9: "Iisdemque temporibus in tres partes medicina diducta est, ut una esset quae uictu, altera quae medicamentis, tertia quae manu mederetur. Primam $\Delta \iota \iota \tau \eta \tau \iota x \eta ́ v ~ s e c u n d a m ~ Ф \alpha \varrho \mu \alpha x \varepsilon v \tau \iota x \eta ́ v ~ t e r t i a m ~ X \varepsilon \iota о v \varrho \gamma i ́ \alpha v$ Graeci nominarunt".

${ }^{8}$ Las principales obras donde Galeno trata de dietética son: De sanitate tuenda (Sobre la conservación de la salud, VI, 1-452 K); De alimentorum facultatibus (Sobre las propiedades de los alimentos, VI, 453-748 K); De probis pravisque alimentorum succis (Sobre los buenos y los malos humores de los alimentos, VI, 749-815 K); De ptisana (Sobre la tisana, VI, 816-831 K).

${ }^{9}$ Cf. Gal., XIX, $491 \mathrm{~K}$. 
la propiedad de lo cálido; la flema, por lo frío; la bilis amarilla, por lo húmedo, y la bilis negra, por lo seco. ${ }^{10}$ Igualmente, los alimentos y las

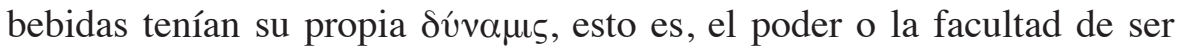
calientes, fríos, húmedos o secos. En consecuencia, era indispensable que el médico supiera exactamente cuál era la cualidad de cada alimento, para que al incluirlo en el régimen alimentario ayudara a preservar el equilibrio corporal o a recobrarlo una vez que éste se había perdido.

Los baños también formaban parte de la dieta. Según las necesidades del paciente, se preescribían los diferentes tipos, pues cada uno tenía propiedades distintas: los baños salados, para calentar y quitar la humedad del cuerpo; los calientes, en ayunas, para adelgazar, pero después de la comida, para calentar y humectar; mientras que los baños fríos, en ayunas, para dar calor y humedad, y, por el contrario, luego de comer, para resecar. ${ }^{11}$ Después de ellos, y para completar el tratamiento, se recomendaba tomar ciertas bebidas, como el apotermo, hecho a base de sémola, vino y frutos secos, cuyo empleo luego del baño caliente pone de manifiesto la etimología de su propio nombre, transcrito del griego

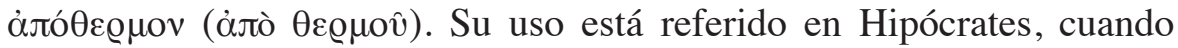
prescribe "que se bañe con agua caliente y que tome apotermo". ${ }^{12}$ En el libro de cocina romano, compilado en el siglo IV de nuestra era, llamado De re coquinaria y atribuido a Apicio, se encuentra la siguiente receta para su preparación:

Así harás el apotermo. La espelta hervida con piñones y almendras peladas y remojadas en agua y lavadas con creta de plata, para que se vuelvan de un blanco semejante. A esto mezclarás uva pasa, vino cocido o vino paso. Por encima rociarás pimienta quebrada y servirás en un tazón. ${ }^{13}$

En dicho recetario también se encuentran otras preparaciones para tomarse a balneo, esto es, "después del baño", como unas "sepias her-

${ }^{10}$ Cf. Gal., XIX, 485-486 K; también I, 509-510 K.

${ }^{11}$ Cf. Hp., Vict., 2, 57.

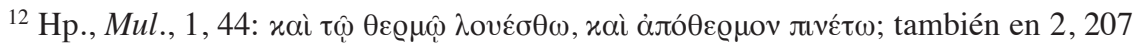
у 209.

${ }^{13}$ Cf. Apic., II, ii, 10: "Apotermvm sic facies. Alicam elixa nucleis et amigdalis depilatis et in aqua infusis et lotis ex creta argentaria, ut ad candorem pariter perducantur. Cui ammiscebis uuam passam, caroenum uel passum. Desuper 〈piper〉 confractum asparges et in boletari inferes". 
vidas para después del baño. Puestas en agua fría $\langle. . .>$ con pimienta, laserpicio, garo, piñones, 〈añadirás〉 huevos, y condimentarás como quieras". ${ }^{14}$

Tales bebidas o caldos eran bien conocidos por sus propiedades laxantes. Hipócrates refiere la naturaleza purgante de los caldos hechos a partir de sepias, pulpos y otros moluscos. ${ }^{15}$ Entre los romanos, Celso recomienda la tinta de la sepia para aliviar el estreñimiento, ${ }^{16}$ y Plinio, además, la prescribe cocida con aceite, sal y harina, para eliminar los parásitos del intestino. ${ }^{17}$

En el De re coquinaria también se encuentra otra receta de carácter purgante para después del baño: una salmuera de erizo; "mezclas garo óptimo a los erizos salados, y parecerán casi frescos, de modo que puedan tomarse después del baño". ${ }^{18}$ La medicina antigua consideraba que los erizos, y el caldo de ellos obtenido, eran alimentos útiles para mover el vientre. ${ }^{19}$

Todas estas recetas constituyen otro de los elementos integrante de la dieta: las purgas. En efecto, alimentos, baños y purgas fueron recursos para limpiar, para purificar el organismo mediante la evacuación de lo innecesario y de lo dañino. Los purgantes mencionados constituían verdaderos remedios para la detoxificación del cuerpo.

\section{Alimentos puros: el aceite de oliva y la miel}

Ahora bien, en materia de alimentos, qué se entiende por "puro". Sin duda el término de inmediato remite a natural, fresco, sin mezcla, sin cocción. Se puede afirmar que el adjetivo puro designa a aquellos alimentos que pueden ingerirse en su estado natural, con ninguna o alguna mínima transformación para su consumo.

${ }^{14}$ Cf. ibid., IX, iv, 3: "Sepias elixas a balneo. In frigidam missas 〈...> cum pipere, lasere, liquamine, nucleis, oua 〈addes〉, et condies ut uoles".

${ }^{15}$ Cf. Hp., Vict., 2, 48, 3.

${ }^{16}$ Cf. Cels., Med., 2, 29, 1-2.

${ }^{17}$ Cf. Plin., H. N., 32, 31, 100-101.

${ }^{18}$ Apic., IX, viii, 5: "Echinis salsis liquamen optimum admisces, et quasi recentes apparebunt, ita ut a balneo sumi possint".

${ }^{19}$ Cf. Cels., Med., 2, 29, 2. 
Cabe mencionar aquí a Claude Lévi-Strauss, quien en el primer volumen de las Mitológicas ${ }^{20}$ propuso el muy conocido triángulo alimentario, para explicar gráficamente la antítesis entre lo crudo/natural/no elaborado y lo cocido/cultural/elaborado. ${ }^{21}$ Se trata de un triángulo equilátero, en el cual cada una de sus puntas corresponde a uno de los estados en el que se presentan los alimentos: crudo, cocido y podrido. En el vértice superior, situó el alimento crudo, el cual pertenece a la esfera de lo natural, pues no hay mediación alguna entre cómo se obtiene de la naturaleza y cómo se lo ingiere. En cambio, en los vértices que, unidos por una línea, forman la base del triángulo, ubicó a la izquierda lo cocido y a la derecha lo podrido. Uno y otro estado son el resultado de una transformación de lo crudo: en el primer caso, lo cocido, mediante la acción humana; en el segundo, lo podrido, como resultado de una transformación natural del alimento. ${ }^{22}$

Ya era creencia entre los autores de la antigüedad grecolatina el valor civilizador del descubrimiento del fuego. Porfirio, por ejemplo, en su tratado Acerca de la abstinencia, afirma que el cambio de la dieta frugal de los antiguos al consumo de carne sólo fue posible gracias al conocimiento del fuego, porque éste permitió cocinarla, pues consumir carne cruda era propio de los impíos, y tenido por un rasgo de salvajismo. ${ }^{23}$ De hecho, Homero, en la Odisea, proporciona una alegoría paradigmática de lo salvaje, cuando describe al cíclope como un prodigio que no

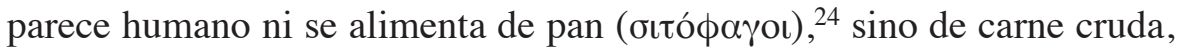
incluso humana, ${ }^{25}$ quien nada siembra ni cultiva los campos. ${ }^{26} \mathrm{La}$ cocción del alimento deviene símbolo de civilización.

En el recetario De re coquinaria de Apicio, lo crudo se expresa por medio de los adjetivos crudus, recens o viridis: el primero, casi siempre

${ }^{20}$ Obra desarrollada en cuatro tomos; cada uno de los tres primeros lleva un sugerente título relacionado con la comida: Lo crudo y lo cocido, La miel y las cenizas, y El origen de las maneras de mesa.

${ }^{21}$ Lévi-Strauss 1997, Mitológicas I; también ofrece una síntesis en Mitológicas III, pp. 416-432, donde, además, agrega el binomio antitético asado/hervido.

${ }^{22}$ Cf. Lévi-Strauss 1997, pp. 416-417.

${ }^{23}$ Cf. Porph., Abst., I, 13.

${ }^{24}$ Od., IX, 190-191.

${ }^{25}$ Ibid., IX, 348.

${ }^{26}$ Ibid., IX, 108. 
referido a huevos crudos (ova cruda) ${ }^{27}$ el segundo, asociado a la fruta, ${ }^{28}$ donde es clara la connotación de "reciente", esto es, "fresca", con ese mismo sentido también se lee carnes recentes ${ }^{29}$ o caseos recentes, ${ }^{30}$ el tercero, viridis es el que aparece un mayor número de veces, pero semánticamente es el término menos extendido, porque siempre está referido a las plantas aromáticas y a las verduras de hoja que, por naturaleza, son de ese color, y también a las olivas y a su jugo. De hecho, cuando dice "aceite verde" (oleum viridem), ${ }^{31}$ Apicio alude tanto al color como a una clase específica de aceite, pero asimismo a las cualidades que denota viridis, en este caso, fresco o recién exprimido.

El aceite, la leche y la miel — de la cual el mismo Lévi-Strauss dirá que es "lo más-que-crudo" 32 - son considerados símbolos por excelencia de lo crudo, lo natural y, en consecuencia, de lo puro.

La miel resulta un alimento completo en sí mismo, que puede comerse en estado natural, sin necesidad de cocinarlo y sin que sea preciso mezclarlo con otros ingredientes. Desde los comienzos de la humanidad, la miel ha sido muy estimada por sus virtudes energéticas. Se considera que provee vigor y energía de manera casi inmediata, porque se absorbe rápidamente por la sangre, lo cual facilita su asimilación. Por este motivo, muy pronto se volvió compañera inseparable de viajeros y peregrinos durante sus largas travesías. Apicio, en el libro primero del $D e$ re coquinaria, nos brinda un testimonio de esto en la receta de un vino cocido con especias y miel (Conditum melizomum uiatorium), especialmente destinado a los viajeros, porque "se conserva eternamente y los que viajan pueden disponer de él durante el camino". ${ }^{33}$

La medicina antigua también se sirvió de la miel por su valor antiséptico y bactericida, pero además por sus cualidades digestivas y laxantes para elaborar tónicos estomacales, como el que aparece en el recetario

${ }^{27}$ Cf. Apic., IV, ii, 12-14; 17; 27; 28; v, 3; VII, vii, 1; VIII, vii, 1; viii, 9; IX, iv, 2. Sólo en una ocasión referido a peces crudos: IV, ii, 27.

${ }^{28}$ Cf. ibid., I, xii, 4.

${ }^{29}$ Cf. ibid., I, viii, 1; también II, ii, 1: adipes fasiani recentes; IV, ii, 13: echinos recentes y echinos recentiores.

${ }^{30} \mathrm{Cf}$. ibid., IV, ii, 13.

${ }^{31}$ Cf. ibid., I, xiv; V, ii, 1-3; iii, 9; IX, x, 2 y 10.

${ }^{32}$ Lévi-Strauss 1997, p. 417.

${ }^{33}$ Apic., I, i, 2: "Conditum melizomum perpetuum quod subministratur per viam peregrinanti”. 
de Apicio, donde se prescribe tomar el agua en la que fueron hervidas acelgas negras, junto con vino y miel. ${ }^{34}$

Quizá también ha influido en la noción de pureza de estos alimentos el hecho de que los antiguos consideraron tanto la miel como el aceite de oliva dones divinos. Aristóteles expresa que la miel caía del aire porque era una exudación del cielo y, por lo tanto, su contacto con los dioses celestes le otorgaba una categoría diferente del resto de los alimentos. ${ }^{35}$ Plinio, por su parte, dice que este líquido era el dulce de los cielos, una saliva emanada de las estrellas o un jugo que exuda el aire mientras se purifica a sí mismo. ${ }^{36}$

El aceite de oliva también era tenido por un regalo de los dioses. Los griegos señalan que Palas Atenea obsequió el olivo a los mortales y enseñó a los habitantes del Ática su cultivo y la obtención de su jugo, el aceite. Cuenta la leyenda que esta deidad se enfrentó a Poseidón por el dominio del Ática; los dioses, entonces, decidieron dirimir el conflicto, otorgando la victoria a quien entregara el don más valioso a los habitantes de la región; así, mientras Poseidón hizo surgir un lago salado cerca de la Acrópolis, Atenea hizo brotar un árbol de olivo junto al Erecteion, lo cual le valió el triunfo. ${ }^{37}$ De hecho, en Atenas ciertos olivos eran sagrados, y se castigaba con la muerte a quien osara arrancar uno de ellos, como lo confirma el discurso de Lisias pronunciado ante los jueces del Areópago. ${ }^{38}$

El aceite de oliva es el jugo, cien por ciento natural, de la aceituna, la cual se prensa ya sea de manera manual o mecánica, para obtenerlo, y para su consumo y para su conservación no hay necesidad de cocción.

En De re coquinaria, el aceite aparece mencionado para condimentar casi cualquier platillo (salado, pero también para confeccionar los dulces y los postres); asimismo fue empleado como conservante. Además, al igual que hoy, el par formado por aceite y sal fue el aliño favorito para

${ }^{34}$ Cf. Apic., III, ii, 3. También, ii, 4.

${ }^{35}$ Cf. Arist., H. A., V, 22-24.

${ }^{36}$ Cf. Pl., H. N., 11, 12.

${ }^{37}$ Cf. Ov., Met., VI, 70-82; Grimal 1981, p. 60.

38 Se trata del discurso séptimo del Corpus lysiacum titulado Areopagítico. Dis-

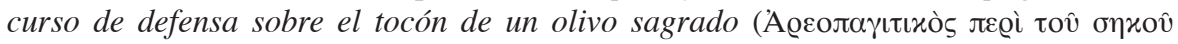

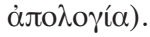


las verduras, ${ }^{39}$ cocidas o crudas, las zanahorias, por ejemplo, se aderezan "con sal, aceite virgen y vinagre": sale, oleo puro et aceto. ${ }^{40}$

En el libro de Apicio, además de hispanum, para referirse al procedente de la Bética, en Hispania, el aceite es calificado con los adjetivos purum ("puro") y viridem ("verde"), en sentido estricto, "verde", pero asimismo "fresco", sobre todo en lenguaje culinario.

Probablemente, al decir oleo puro Apicio se refería al aceite que hoy correspondería a un aceite de oliva virgen extra, es decir, al jugo de la aceituna, prensado en frío, sin ningún defecto sin adicionar ningún elemento ni someterlo a fuente de calor alguna. Estas condiciones en la antigüedad eran sumamente difíciles de lograr. De aquí que fuera una práctica frecuente corregir el mal sabor u olor del aceite, añadiéndole sal, hierbas aromáticas o cera líquida derretida en un aceite de óptima calidad..$^{41}$ Por ello, se hacía verdaderamente necesario aclarar si el aceite era "puro".

Además en medicina ${ }^{42}$ y en cosmética también era indispensable distinguir los óleos (oleum) de los ungüentos (unguentum), ya que como precisa Isidoro de Sevilla: "El aceite es puro y no está mezclado con ninguna otra cosa. En cambio, el ungüento es todo aquello que, confeccionado a partir del aceite común, es enriquecido por la mezcla de diversas especias". ${ }^{43}$

\section{La purificación por medio del alimento}

Desde tiempos remotos, el hombre estableció una relación directa entre el alimento que ingiere y las consecuencias físicas, morales y espiritua-

${ }^{39}$ Cf. el libro tercero del De re coquinaria, "Cepuros", cuyas recetas constituyen ejemplo de ello.

${ }^{40}$ Apic., III, xxi, 2.

${ }^{41}$ Cf. Paladio, XII, 19-21.

${ }^{42}$ Los antiguos lo emplearon, según refiere Plinio (H. N., XXIII, 69-80), para mejorar el funcionamiento del aparato digestivo, para la cicatricación de heridas, úlceras y quemaduras, para la protección de la piel y para mitigar contracturas y dolores musculares, por sus efectos emolientes.

${ }^{43}$ Isid., Orig., IV, 12, 6: "Oleum est purum nullique rei admixtum. Vnguentum vero est omne quod ex communi oleo confectum aliarum specierum commixtione augetur". Las cursivas del español son de la autora. 
les que conlleva el acto de comerlo: Adán y Eva fueron expulsados del Paraíso, por haber comido un alimento prohibido.

De aquí que para muy distintas religiones y doctrinas filosóficas, fuera una verdadera preocupación, y motivo de amplias disertaciones, qué alimentos permitir y cuáles prohibir, en especial en la dieta cotidiana de sacerdotes y filósofos, a fin de mantener la pureza del alma. Son bien conocidas las prohibiciones de los pitagóricos respecto al consumo de habas; ${ }^{44}$ las del hinduísmo, referidas a la carne de vaca; ${ }^{45}$ así como las rigurosas leyes dietéticas, contenidas en el capítulo once del Levítico, las cuales, además del rechazo al consumo del cerdo y otros animales, dan lugar a la cocina kósher entre los judíos.

Porfirio en Acerca de la abstinencia sintetiza las prácticas y prohibiciones alimentarias de judíos, ${ }^{46}$ lacedemonios, ${ }^{47}$ egipcios ${ }^{48}{ }^{4 i r i o s},{ }^{49}$ persas $^{50}$ e hindúes, ${ }^{51}$ todos estos pueblos prescriben para sus religiosos la abstinencia total, o de ciertas clases, de carne. Los cristianos también adoptaron la práctica de la abstinencia de carne, convertida en el ayuno, exigido durante la Cuaresma, pero elegido como régimen de vida por anacoretas y cenobitas. ${ }^{52}$

El libro de Porfirio es una verdadera apología del vegetarianismo, pues el autor considera que la alimentación cárnica no es recomendable porque su consumo incita las pasiones: "por tanto, hay que abstenerse [...] también de ciertos alimentos, los cuales, por su naturaleza, pueden despertar las pasiones de nuestra alma". ${ }^{53}$ Por el contrario, "el alimento sin carne y sencillo y fácil de conseguir para todos nos libera, nos pro-

${ }^{44}$ Respecto a la prohibición de comer habas, cf. Empédocles (fr. 141 Diels-Kranz), Aristoxeno (fr. 25 Wehrli), Diógenes Laercio (8, 34 y 45), Calímaco (fr. 553 Pfeiffer), Cicerón (Div., I, XXX, 62) y Aulo Gelio (N. A., 4, 11).

${ }^{45}$ Cf. Marvin Harris 2010, pp. 15-37.

${ }^{46}$ Cf. Porph., Abst., IV, 11-13.

${ }^{47}$ Cf. Porph., op. cit., IV, 3-5, extractado Licurgo (XII) de las Vidas paralelas de Plutarco.

${ }^{48}$ Cf. Porph., Abst., IV, 6-7.

${ }^{49}$ Cf. ibid., IV, 15.

${ }^{50} \mathrm{Cf}$. ibid., IV, 16.

${ }^{51}$ Cf. ibid., IV, 17.

${ }^{52}$ Cf. Gonzalo del Cerro Calderón 2000, pp. 106-124.

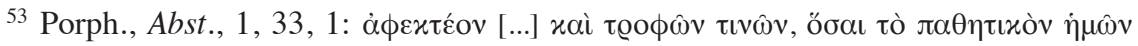

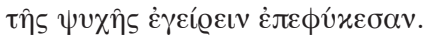


cura la salvación, dado que proporciona paz a nuestro razonamiento". ${ }^{4}$ Según se advierte en las palabras de Porfirio, la observancia de un régimen alimenticio concierne más a la esfera de lo moral que a la de lo estrictamente alimentario.

Es claro que la dicotomía entre carne/gula/pecado y fruto/frugalidad/ pureza no es exclusiva del cristianismo primitivo y la primera patrística: muchos pueblos de la antigüedad consideraron la sobriedad en la alimentación una condición necesaria para una vida moral virtuosa.

El concepto "dieta frugal" se refiere stricto sensu a la alimentación que se basa en los frutos de la tierra, esto es, semillas, miel, plantas y frutas, todos ellos podían consumirse en su estado natural, sin necesidad de mezcla ni cocción y, por ello, eran considerados puros, como ya dijimos. Sin embargo, lato sensu la frugalidad alude a un estilo de vida guiado por la sobriedad y la moderación de costumbres, incluidas las alimenticias. Por ello, dado que lo que se come tiene consecuencias directas sobre nuestro cuerpo, tanto por el proceso de la digestión como por la estimulación de los sentidos, el seguir un régimen frugal, en todos los hábitos cotidianos, permite mantener al cuerpo en el terreno de la pureza.

En consecuencia, la dieta frugal tuvo un papel determinante para la medicina, pero también para la filosofía ${ }^{55}$ y para las religiones de la antigüedad, porque no sólo pretende preservar el equilibrio corporal a fin de mantener la salud, ${ }^{56}$ busca además un fin más trascendente: la pureza de espíritu.

La alimentación frugal lleva a la purificación del organismo, a un proceso digestivo rápido, a estar ligero, a mantenerse despierto, a la parquedad y a la mesura, de aquí que moralmente sea considerada buena. Por

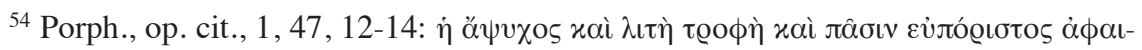

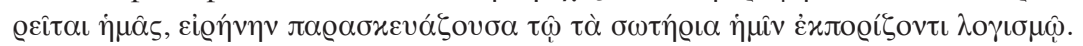

55 Filósofos como Platón (Phdr., 270 b-c.), Aristóteles (Pr., 1, 2; 4; 13;-15; 37; 48), Plutarco (Moralia, 2, 11: De tuenda sanitate praecepta; 12, 68: De esu carnium), Jámblico $(V P, 16,68 ; 24,106-109)$, entre otros, trataron acerca de la alimentación.

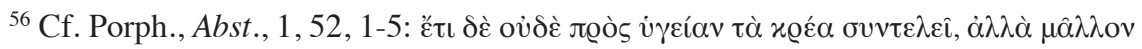

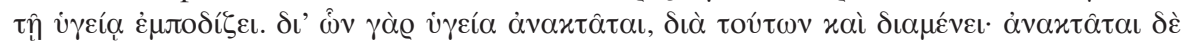

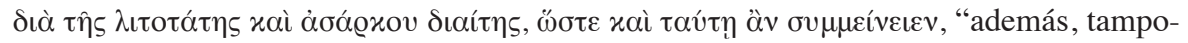
co contribuye la carne para la salud, sino más bien impide la salud. Pues por los medios que la salud se recobra, por ellos también permanece: la salud se recobra por medio de una dieta sencilla y sin carne, de modo que también con ésta [sc. una dieta sencilla y sin carne] se conserva". 
el contrario, la alimentación cárnica, estimula los sentidos, provoca una digestión lenta, ocasiona que la pesadez y el sueño se apoderen del organismo.$^{57}$ Más aún, la abstinencia de carne y la frugalidad hacen posible en mayor medida un desprendimiento de lo material y corpóreo a fin de acercarse a la divinidad ${ }^{58}$ y lograr la pureza de cuerpo y espíritu. ${ }^{59}$

\section{BIBLIOGRAFÍA}

Apicius, De re coquinaria, text. ét., trad. et comm. Jacques André, París, "Les Belles Lettres", 1987 [1a. ed. 1974] (Collection des Universités de France, Guillaume Budé), XXXII + 234 págs.

Celsus, De Medicina, engl. trans. W. G. Spencer, London-Cambridge (Mass.), William Heinemann / Harvard University Press, 1948 (The Loeb Classical Library), 3 vols.

Cerro Calderón, Gonzalo del, "Condicionamientos de la dieta mediterránea en la moral patrística", en Aurelio Pérez Jiménez y Gonzalo Cruz Andreotti (eds.), Dieta mediterránea. Comidas y hábitos alimenticios en las culturas mediterráneas, Madrid, Ediciones Clásicas, 2000 (Mediterranea, 6), pp. 103-124.

Galenus, Opera omnia, ed. cur. C. G. Kühn, Hildesheim-Zürich-New York, Georg Olms Verlag, 2001.

Grimal, Pierre, Diccionario de mitología griega y romana, Barcelona, Paidós, 1981.

HARRIS, Marvin, Vacas, cerdos, guerras y brujas, Madrid, Alianza, 2010.

Hippocrate, Du Régime, text. ét. et trad. Robert Joly, Paris, Les Belles Lettres, 1967.

HIPPOCRATES, De mulierum affectibus I-III, Oeuvres completes d'Hippocrate, vol. 8, ed. E. Littré, Paris, J. B. Bailliere, 1853 (CD-ROM, Thesaurus Linguae Graecae).

—, v. II: Regimen in acute diseases; v. IV: Regimen, engl. trans. W. H. S. Jones, Cambridge (Mass.)-London, Harvard University Press / William Heinemann, 1967 (The Loeb Classical Library).

Homer, The Odyssey, engl. trans. A. T. Murray, Cambridge (MA)-London, Harvard University Press / William Heinemann, 1919 [texto griego en versión digital, recuperado de https://www.hs-augsburg.de/ harsch/graeca/Chronologia/S_ ante08/Homeros/hom_od00.html].

Isidoro de SEvilla, Etimologías, text. lat., vers. esp., nts. e índ. José Oroz Reta y Manuel A. Marcos Casquero, Madrid, Editorial Católica, 1983 (Biblioteca de Autores Cristianos), 2 vols.

${ }^{57}$ Cf. Porph., Abst., I, 27-28.

${ }^{58}$ Cf. ibid., I, 54 y 57.

${ }^{59} \mathrm{Cf}$. ibid., IV, 20. 
LÉvi-Strauss, Claude, Mitológicas, tomo I, Lo crudo y lo cocido; tomo III: El origen de las maneras de mesa, México, Siglo XXI, 1997.

Lisias, Discursos (Areopagítico. Discurso de defensa sobre el tocón de un olivo sagrado), intr., trad. y nts. José Luis Calvo Martínez, Madrid, Gredos, 1988 (Biblioteca Clásica Gredos, 122).

Palladius Rutilius Taurus Aemilianus, Opus agriculturae, ed. J. C. Schmitt, Leipzig, Teubner, 1898 [texto latino en versión digital, recuperado de http:// www.forumromanum.org/literature/palladius/agr.html].

PuINY, Natural History, engl. trans. H. Rackham (I-V, IX), W. H. S. Jones (VI-VIII), D. E. Eichholz (X), London-Cambridge (Mass.), William Heinemann / Harvard University Press, 1951, 1956, 1958-1963 (The Loeb Classical Library), 10 vols.

Porfirio, Sobre la abstinencia, trad., intr. y nts. Miguel Periago Lorente, Madrid, Gredos, 1984 (Biblioteca Clásica Gredos, 69).

Porphyre, De l'abstinence, intr. Jean Bouffartigue et Michel Patillon, text. ét. et trad. Jean Bouffartigue, Paris, Les Belles Lettres, 1977. 
